\title{
Nitridergic Modulation of the Antinociceptive Activity of Rosuvastatin in Mice
}

\author{
Viviana Noriega $^{1,2}$, Fernando Sierralta ${ }^{3,4}$, Juan Carlos Prieto ${ }^{2,4}$, Pilar Zanetta ${ }^{4}$, Hugo F. Miranda ${ }^{1,4^{*}}$ \\ ${ }^{1}$ Faculty of Medicine, Pharmacy School, Universidad Andres Bello, Santiago, Chile; ${ }^{2}$ Cardiovascular Department, Clinical Hospital, \\ Universidad de Chile, Santiago, Chile; ${ }^{3}$ Faculty of Odontology, Universidad Finis Terrae, Santiago, Chile; ${ }^{4}$ Molecular and Clinical \\ Pharmacology Program, Faculty of Medicine, Medical School, Universidad de Chile, Santiago, Chile. \\ Email: "hmiranda@med.uchile.cl
}

Received November $29^{\text {th }}, 2013$; revised December $29^{\text {th }}$, 2013; accepted January $11^{\text {th }}, 2014$

Copyright (C) 2014 Viviana Noriega et al. This is an open access article distributed under the Creative Commons Attribution License, which permits unrestricted use, distribution, and reproduction in any medium, provided the original work is properly cited. In accordance of the Creative Commons Attribution License all Copyrights @ 2014 are reserved for SCIRP and the owner of the intellectual property Viviana Noriega et al. All Copyright (C) 2014 are guarded by law and by SCIRP as a guardian.

\section{ABSTRACT}

Statins, 3-hydroxy-3 methylglutaryl coenzyme A (HMG-CoA) reductase enzyme inhibitors, are lipid-lowering drugs, often used in the treatment of cardiovascular diseases (hyperlipidemia, atherosclerosis). It has been shown that statins have antiinflammatory effects independent of their lipid-lowering effects and these anti-inflammatory effects inhibit the inflammation and pain process. This study evaluated the antinociceptive and anti-inflammatory effects of rosuvastatin using the acetic acid writhing, the formalin hind paw, the orofacial formalin and the hot plate tests. The following experimental group were used: control, acute (1 day) and chronic ( 3 days) after oral gavage with rosuvastatin $(3,10,30,100$ and $300 \mathrm{mg} / \mathrm{kg})$. Rosuvastatin produced a dose-dependent antinociception, with different potency, in all the tests. Additionally, nitric oxide synthase inhibitors (Abbreviationsand aminoguanidine) were used to assess the nitric oxide participation on this induced rosuvastatin antinociception. The data demonstrated the antinociceptive and anti-inflammatory activity of rosuvastatin in algesiometer models of tonic or phasic pain. These activities seem to be induced by modulation of iNOS expression, a result that may be relevant in the pharmacological treatment of human pain where rosuvastatin and nitric oxide synthase inhibitors must be used.

\section{KEYWORDS}

Antinociception; Anti-Inflammation; Algesiometer Assays; Rosuvastatin; L-NAME; Aminoguanidine

\section{Introduction}

Management of different types of pain (acute or chronic) is the most frequent issue encountered by clinicians and pharmacological therapy and is the first line of approach for the treatment of pain [1]. The common drugs used to relieve pain, are opioids, nonsteroidal anti-inflammatory drugs (NSAIDs) and co-analgesics or adjuvant analgesics such as antidepressants (e.g. amitriptyline, clomipramine, imipramine, nortriptyline, duloxetine) anticonvulsants (e.g.carbamazepine, gabapentin, pregabalin, oxcarbazepine, lamotrigine, phenytoin, acid valproic, topiramate), cannabinoids, ketamine and others. Although the understanding of pain mechanisms has recently improved sig-

${ }^{*}$ Corresponding author. nificantly, much more is yet to be awaited.

Multiple neurotransmitters and other mediators are involved in the endogenous modulation of pain signaling, providing numerous opportunities for intervention with different classes of analgesics. Thus, endogenous opioids are key mediators in the descending pain suppression pathways. Additionally, monoaminergic neurotransmitters such as norepinephrine, serotonin and dopamine positively or negatively modulate pain signaling, depending on the receptor type and location. The various mediators involved in pain signaling, provide potential targets for pharmacological interventions. These data support current guidelines which endorse multiple-mechanism strategies for both acute and chronic pain management [1]. 
Recently, studies have been conducted evaluating the antinociceptive effects of some statins (e.g. atorvastatin, simvastatin, rosuvastatin) in several models of algesiometer tests of mice [2-4]. However, rosuvastatin induced antinociceptive activity in the acetic acid writhing and formalin tests while there was no significant activity in the hot-plate test [4]. In addition, there are several studies reporting nitric oxide (NO) in the rosuvastatin effects [5-7]. The purpose of this study was to evaluate the involvement of L-NAME, a known NO-synthase (NOS) inhibitor and aminoguanidine, an irreversible inhibitor of iNOS in the antinociceptive and anti-inflammatory effects of rosuvastatin in five animal pain models. Rosuvastatin was selected because it is one of the most prescribed and potent statins, additionally it is one of the most favorable safety profile of these types of drugs available.

\section{Materials and Methods}

Male CF-1 mice (30 g), housed in a $12 \mathrm{hr}$, light-dark cycle at $22^{\circ} \mathrm{C} \pm 2{ }^{\circ} \mathrm{C}$ with ad libitum access to food and water. Experiments were performed in accordance with current guidelines for the care of laboratory animals and ethical guidelines for investigation of experimental pain, approved by the Animal Care and Use Committee of the Faculty of Medicine, University of Chile. Animals were acclimatized to the laboratory for at least $2 \mathrm{~h}$ before testing, each animal was used only once during the protocol and sacrificed immediately after the algesiometric test. The number of animals was kept at a minimum compatible with consistent effects of the drug treatments.

\subsection{Writhing Test}

The procedure that was used has been previously described [3]. Mice were treated per os (p.o.) daily with saline or rosuvastatin for 1 or 3 days before the assays and then injected intraperitoneally (i.p.) with $10 \mathrm{~mL} / \mathrm{kg}$ of $0.6 \%$ acetic acid solution. A writhe is characterized by a wave of contraction of the abdominal musculature followed by the extension of the hind limbs. The number of writhes in a 5 min period was counted, starting $5 \mathrm{~min}$ after the acetic acid administration. Antinociception was expressed as inhibition percentage of the number of writhes observed in control animals $(20.1 \pm 0.28, n=12)$.

\subsection{Tail-Flick Test}

This algesiometric test was similar to that previously described [3]. A radiant heat, automatic tail flick algesiometer (U. Basile, Comerio, Italy) was used to measure response latencies. The light beam was focused on the animal's tail about $4 \mathrm{~cm}$ away from the tip and the intensity was adjusted so that baseline readings were between
2 and 3 s. An 8 s cut-off time was imposed to avoid damage to the tail. Control reaction time (latency of the response) was recorded twice, with an interval of $15 \mathrm{~min}$ between readings; the second reading was similar to the first. Only animals with baseline reaction times between 2 and $3 \mathrm{~s}$ were used for the experiments. Tail-flick latencies were converted to the $\%$ of maximum possible effect (MPE) as follows:

MPE\% = (postdrug latency-predrug latency $/$ (cut-off time-predrug latency) $\times 100$

Each animal was used as its own control and treated p.o. daily with saline or rosuvastatin for 1 or 3 days before the assays. The of antinociception was expressed as MPE (ED50) and was calculated from the dose that produced $50 \%$ linear regression analysis of the curve obtained by plotting log dose versus MPE\%.

\subsection{Formalin Test in the Hind Paw}

The method described by Miranda et al. [3] was used. To perform the test, $20 \mu \mathrm{L}$ of $2 \%$ formalin solution were injected subcutaneously into the dorsal surface of the mice's right hind paw with a 27-gauge needle attached to a $50 \mu \mathrm{L}$ Hamilton syringe. Each mouse was immediately returned to the observation chamber. The degree of pain intensity was determined as the total time spent by the animal licking or biting the injected hind paw, measured by visual observation and a digital time-out stopwatch. The test shows two clear cut phases; phase I corresponds to the 5 min period starting immediately after the formalin injection and represents a tonic acute pain due to peripheral nociceptor sensitization and phase II was recorded as the 10 min period starting 20 min after the formalin injection and represents inflammatory pain. Mice were treated per os (p.o.) daily with saline or rosuvastatin for 1 or 3 days before formalin injection. Saline control animals $(140.50 \pm 6.55 \mathrm{sec}$ and $165.00 \pm 7.50 \mathrm{sec}$, for phase I and phase II, respectively, with $n=12$, for each phase). For each drug, analgesic effects were characterized after the administration of a minimum of four doses in logarithmic increments. The licking times observed were converted to a \% of maximum possible effect (MPE) as follows:

MPE $\%=100-(100 \times$ postdrug total licking time $) /$ (control total licking time).

The dose that produced 50\% of MPE (ED50) was calculated from the linear regression analysis of the curve obtained by plotting log dose versus MPE\%.

\subsection{Orofacial Formalin Test}

A modification of the method described by Luccarini et al. [8] was used. To perform the test, $20 \mu \mathrm{L}$ of $2 \%$ formalin solution was injected into the upper right lip of each mouse, with a 27 gauge needle. This formalin solu- 
tion induced a consistent behavior and the possibility to produce less tissue damage. The mice were immediately returned to the observation chamber. The degree of pain intensity was determined as the total time period that the animal spent rubbing its lip with one of its extremities. Saline or rosuvastatin was administered p.o. daily prior to the administration of formalin for 1 or 3 days before the assays. Two distinct phases were identified during the test; phase I corresponds to the 5 min period starting immediately after formalin injection and represents a tonic acute pain due to peripheral nociceptor sensitization. Phase II was recorded as the $10 \mathrm{~min}$ period starting 20 min after formalin injection and represents inflammatory pain. Each drug effect was characterized after the administration of at least four doses in logarithmic increments. Maximum possible effect (MPE), which represents antinociception, was calculated as follows:

MPE\% $=100-[(100 \times$ postdrug grooming time $/[$ control rubbing time)].

The dose that produced 50\% of MPE (ED50) was calculated from the linear regression analysis of the curve obtained by plotting log dose vs. MPE\%. Thre grooming time of mice control was $124.50 \pm 4.55 \mathrm{sec}(\mathrm{n}=12)$ and $158.00 \pm 4.15 \mathrm{sec}(\mathrm{n}=12)$ for phase I and phase II, respectively.

\subsection{Hot-Plate}

The hot-plate test was performed using the method described by previously [3]. In this case, the animals were free to move and the assay temperature was $45^{\circ} \mathrm{C} \pm 1^{\circ} \mathrm{C}$. The animal behavior as a sign of pain was licking the forelegs or jumping off the hot plate. The base line latency for this behavior was recorded with a stop-watch. The cut-off time was fixed at 30 sec to avoid skin damage. Several measurements were performed with a $3 \mathrm{~min}$ interval: two at baseline (without any drug) and two after p.o. administration of the test drug. Hot-plate latencies were converted to a maximum possible effect \% (MPE) as in the tail-flick assays. The control latency was 19.50 \pm 1.50 sec $(n=12)$.

\subsection{Analysis of the Interaction Rosuvastatin with L-NAME or Aminoguanidine}

The nature of the antinociceptive interaction of rosuvastatin was evaluated in the presence of L-NAME (1 or 5 $\mathrm{mg} / \mathrm{kg}$, i.p.), or aminoguanidine (50 or $100 \mathrm{mg} / \mathrm{kg}$, i.p.). This type of analysis has been validated to establish the presence and type of interaction between two drugs, when one of them is inactive or does not generate a dose-response curve [9,10].

\subsection{Protocol}

Dose-response curves for rosuvastatin, before and after pretreatment with 1 or $5 \mathrm{mg} / \mathrm{kg}$ of L-NAME, i.p. and with 50 or $100 \mathrm{mg} / \mathrm{kg}$ of aminoguanidine i.p., were obtained using at least six animals for each of at least four doses. A least squares linear regression analysis of the log dose response curve allowed the calculation of the doses that produced $50 \%$ of antinociception for each statin alone.

\subsection{Drugs}

Rosuvastatin was freshly dissolved in saline and administered per os (p.o.) in doses of 3, 10, 30, 100 and 300 $\mathrm{mg} / \mathrm{kg}$ and was obtained from local Astra Zeneca S.A. L-NAME hydrochloride and aminoguanidine hydrochloride were purchased from Sigma Chemical Co, St. Louis, MO, USA. Doses were expressed on the basis of the salt.

\subsection{Statistical Analysis}

Results are presented as ED50 values \pm S.E.M. The program used to perform statistical procedures was Pharm Tools Pro (version 1.27, The McCary Group Inc., PA, USA). Results were analyzed by Student's test. p values lower than 0.05 ( $p<0.05$ ) were considered statistically significant.

\section{Results}

Animals tested with different doses of rosuvastatin did not exhibit an observable motor dysfunction. L-NAME (1 or $5 \mathrm{mg} / \mathrm{kg}$, i.p.) or aminoguanidine (50 or $100 \mathrm{mg} / \mathrm{kg}$, i.p.) had no effect compared to the respective control value of the different algesiometer tests.

\subsection{Antinociception in the Writhing Test}

The daily p.o. administration for 1 and 3 days of rosuvastatin induced a dose-dependent antinociceptive effects with different potencies in the writhing test of mice, with an $\mathrm{ED}_{50}$ of $17.08 \pm 2.24$ and $19.13 \pm 2.43 \mathrm{mg} / \mathrm{kg}$ at day 1 and 3, respectively (see Table 1). Rosuvastatin was 1.12 fold more potent at days 3 than 1 . The corresponding doseresponse curves for rosuvastatin are displayed in Figure 1(a). In the presence of 1 or $5 \mathrm{mg} / \mathrm{kg}$, i.p. of L-NAME, the $\mathrm{ED}_{50}$ values obtained for rosuvastatin were $19.10 \pm$ 1.09 and $21.55 \pm 2.51 \mathrm{mg} / \mathrm{kg}$ on days 1 and 3 respectively. Also, in the presence of 50 or $100 \mathrm{mg} / \mathrm{kg}$, i.p. of aminoguanidine, the $\mathrm{ED}_{50}$ of rosuvastatin obtained were $20.8 \pm$ 3.50 and $19.50 \mathrm{mg} / \mathrm{kg}$ on days 1 and 3, rerspectively, as shown in Table 1 . The results show L-NAME and aminoguanidine decrease the potency of rosuvastatin.

\subsection{Antinociception in the Tail-Flick Test}

The administration of rosuvastatin for 1 or 3 days prior to the tail-flick test induced dose-dependent antinociceptive 
Table 1. $\mathbf{E D}_{50}$ values $(\mathrm{mg} / \mathrm{kg} \pm$ S.E.M.) for oral gavage administration of rosuvastatin in the writhing test (WT), tail flick (TF), formalin hind paw (FP), orofacial formalin (OF) and hot plate (HP) assays in mice. Effect of L-NAME 1or 5 mg/kg and aminoguanidine (AMG) 50 or $100 \mathrm{mg} / \mathrm{kg}$.

\begin{tabular}{|c|c|c|c|c|c|c|c|c|}
\hline \multicolumn{9}{|c|}{$\mathrm{ED}_{50} \pm$ S.E.M. } \\
\hline Assay & & Control & 1 day & 3 days & L-NAME 1 & L-NAME 5 & AMG 50 & AMG 100 \\
\hline WT & & $20.1 \pm 0.45$ & $17.08 \pm 2.24$ & $19.13 \pm 2.43$ & $19.10 \pm 1.09$ & $21.55 \pm 2.51$ & $20.8 \pm 3.50$ & $19.50 \pm 3.80$ \\
\hline $\mathrm{TF}$ & & N/A & $61.27 \pm 5.92$ & $55.26 \pm 7.74^{*}$ & $118.23 \pm 5.8^{*}$ & $97.92 \pm 3.89^{\Lambda+}$ & $125.80 \pm 5.78^{*}$ & $130.65 \pm 11.08^{\mathbf{\Lambda}}$ \\
\hline \multirow[t]{2}{*}{ FP } & Phase I & $140.50 \pm 6.55$ & $35.11 \pm 4.88$ & $31.01 \pm 5.10$ & $92.98 \pm 0.78^{*}$ & $82.66 \pm 5.81^{\wedge}$ & $110.24 \pm 12.36^{*}$ & $125.57 \pm 8.59^{\mathbf{\Lambda} \times}$ \\
\hline & Phase II & $165.00 \pm 7.50$ & $26.31 \pm 5.29$ & $17.37 \pm 1.36^{*}$ & $38.12 \pm 3.71^{*}$ & $75.64 \pm 6.32^{\Lambda+}$ & $135.84 \pm 9.87^{*}$ & $158.39 \pm 8.21^{\Delta \times}$ \\
\hline \multirow[t]{2}{*}{ OF, } & Phase I & $124.50 \pm 4.55$ & $14.50 \pm 2.34$ & $13.06 \pm 0.40$ & $68.56 \pm 8.93^{*}$ & $65.78 \pm 3.12^{\wedge}$ & $112.53 \pm 5.37^{*}$ & $104.57 \pm 9.87^{\mathbf{\Lambda}}$ \\
\hline & Phase II & $158.00 \pm 4.15$ & $11.68 \pm 1.01$ & $10.71 \pm 1.33$ & $71.54 \pm 5.75^{*}$ & $85.22 \pm 5.45^{\mathbf{\Lambda}+}$ & $139.71 \pm 8.76^{*}$ & $157.25 \pm 10.67^{\Delta \times}$ \\
\hline HP & & $19.50 \pm 1.50$ & $48.94 \pm 6.79$ & $36.83 \pm 1.81^{*}$ & $28.57 \pm 8.12^{*}$ & $29.36 \pm 6.78$ & $31.81 \pm 5.91^{*}$ & $42.54 \pm 5.62^{\boldsymbol{\Lambda} \times}$ \\
\hline
\end{tabular}

${ }^{*} \mathrm{p}<0.05$ compared with 1 day; ${ }^{\boldsymbol{\Delta}} \mathrm{p}<0.05$ compared with day $3 ;{ }^{+} \mathrm{p}<0.05$ compared with L-NAME 1 mg/kg; ${ }^{\mathbf{x}} \mathrm{p}<0.05$; compared with AMG 50 mg/kg.All results are significant $(\mathrm{P}<0.05)$ compared with the control, with the exception of the WT.

activity as can be seen in Figure 1(b). The $\mathrm{ED}_{50}$ for MPE were $61.27 \pm 5.92$ and $55.26 \pm 7.74$ on days 1 and 3 respectively, are shown in Table 1 . Rosuvastatin was 1.10 fold more potent at days 3 than 1 . The corresponding dose-response curves for rosuvastatin are displayed in Figure 1(b). In this assay, a significant difference was obtained, between the antinociceptive effect of rosuvastatin after 1 and 3 daily of treatments. The analgesic effect of rosuvastatin after the pretreatment of mice with 1 or $5 \mathrm{mg} / \mathrm{kg}$, i.p. of L-NAME was inhibited significantly with an $\mathrm{ED}_{50}$ of $118.23 \pm 5.81$ and $97.92 \pm 3.89 \mathrm{mg} / \mathrm{kg}$ on both days. Also, in the presence of 50 or $100 \mathrm{mg} / \mathrm{kg}$, i.p. of aminoguanidine, the $\mathrm{ED}_{50}$ of rosuvastatin obtained were $125.80 \pm 5.78$ and $130.65 \pm 11.08 \mathrm{mg} / \mathrm{kg}$ on days 1 and 3 , rerspectively, as shown in Table 1 . The results show L-NAME and aminoguanidine decrease the potency of rosuvastatin, as can be seen in Table 1 .

\subsection{Antinociception in the Hot-Plate Assay}

The daily administration during 1 and 3 days of rosuvastatin induced a dose-dependent antinociceptive effect in the hot plate test of mice, see Figure $1(\mathrm{c})$. The $\mathrm{ED}_{50}$ values obtained were $48.94 \pm 6.79$ and $36.83 \pm 1.81$ $\mathrm{mg} / \mathrm{kg}$ at days 1 and 3 respectively. Rosuvastatin was 1.32 fold more potent at days 3 than 1 . The antinociceptive activity of rosuvastatin after the pretreatment of mice with 1 or $5 \mathrm{mg} / \mathrm{kg}$, i.p. of L-NAME was inhibited significantly on both days of p.o. administration of the statin, with an $\mathrm{ED}_{50}$ of $28.57 \pm 8.12$ and $29.36 \pm 6.78$, g/kg, on days 1 and 3 respectively. Also, in the presence of 50 or $100 \mathrm{mg} / \mathrm{kg}$, i.p. of aminoguanidine, the $\mathrm{ED}_{50}$ of rosuvastatin obtained were $31.81 \pm 5.91$ and $42.54 \pm 5.62 \mathrm{mg} / \mathrm{kg}$ on days 1 and 3, rerspectively, as shown in Table 1 . The results show L-NAME and aminoguanidine decrease the potency of rosuvastatin as can be seen in Table 1 .

\subsection{Antinociception in the Orofacial Formalin Test}

The administration of rosuvastatin for 1 or 3 days prior to the orofacial formalin test induced dose-dependent antinociceptive activity during phase I and II of the formalin as can be seen in Figures 2(a) and (b). The corresponding $\mathrm{ED}_{50}$ for MPE were $14.50 \pm 2.34$ and $13.06 \pm 0.40$ for phase I on days 1 and 3 respectively, and $11.68 \pm$ 1.01 and $10.71 \pm 1.33$ for phase II, on days 1 and 3 , respectively as are shown in Table 1 . Rosuvastatin was 1.11 and 1.09 fold more potent at days 1 than 3 , in phase I and II, respectively. The anti-inflammatory effect of rosuvastatin after the pretreatment of mice with 1 or 5 $\mathrm{mg} / \mathrm{kg}$, i.p. of L-NAME was inhibited significantly with an $\mathrm{ED}_{50}$ of $68.56 \pm 8.93$ and $65.78 \pm 3.12 \mathrm{mg} / \mathrm{kg}$, in phase I at days 1 and 3, respectively and to $71.54 \pm 5.75$ and $85.22 \pm 5.45 \mathrm{mg} / \mathrm{kg}$, in phase II at days 1 and 3 , respectively (see Table 1). When the antinociception of rosuvastatin was measured in the presence of 50 or 100 $\mathrm{mg} / \mathrm{kg}$ aminoguanidine, the $\mathrm{ED}_{50}$ obtained were of 112.53 \pm 5.37 and $104.57 \pm 9.87 \mathrm{mg} / \mathrm{kg}$, in phase I at days 1 and 3 , respectively and to $139.71 \pm 8.76$ and $157.25 \pm 10.67$ $\mathrm{mg} / \mathrm{kg}$, in phase II at days 1 and 3 , respectively (see Table 1).

\subsection{Antinociception in the Formalin Hind Paw Test}

The administration during 1 and 3 days of rosuvastatin showed dose-dependent antinociceptive effects with different potencies in the formalin hind paw test, both in phase I and phase II. The dose-response curves obtained during 1 and 3 days of treatment with rosuvastatin in the test can be seen in Figures 3(a) and (b). The ED50 obtained were $35.11 \pm 4.88$ and $31.01 \pm 5.10 \mathrm{mg} / \mathrm{kg}$, in 


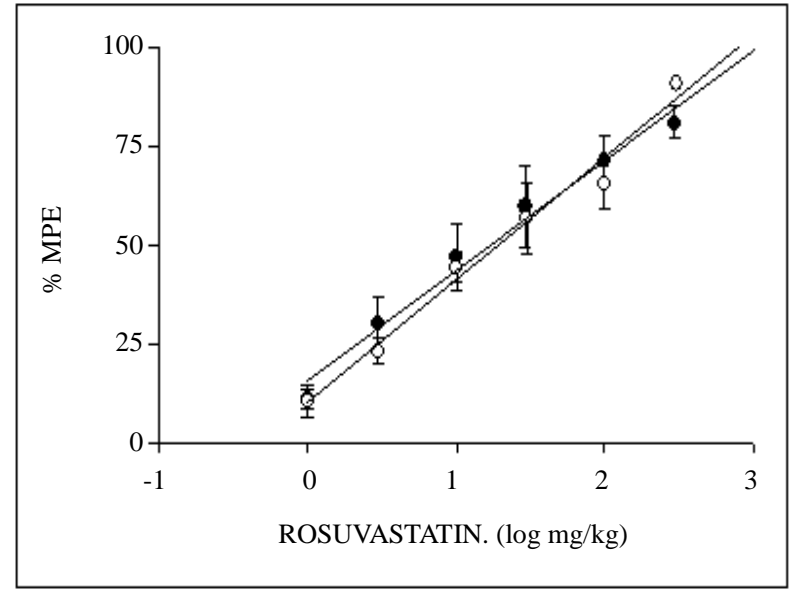

(a)

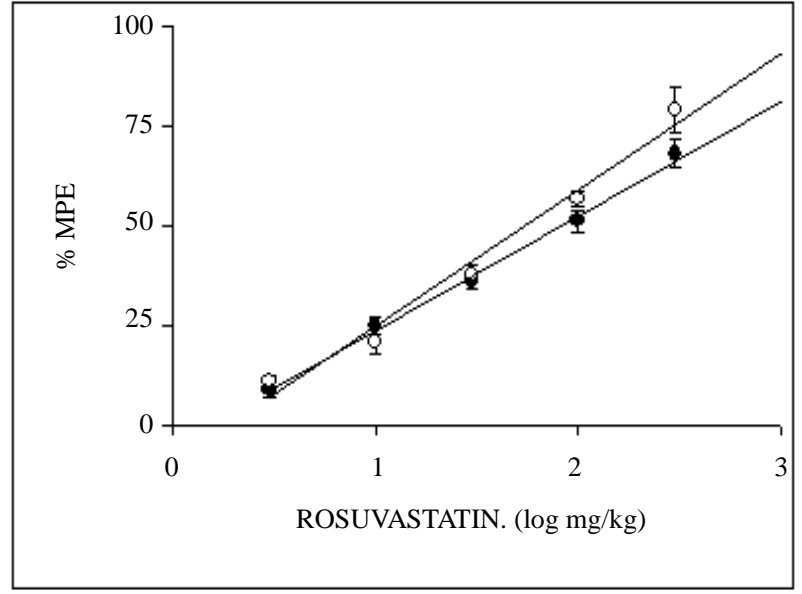

(b)

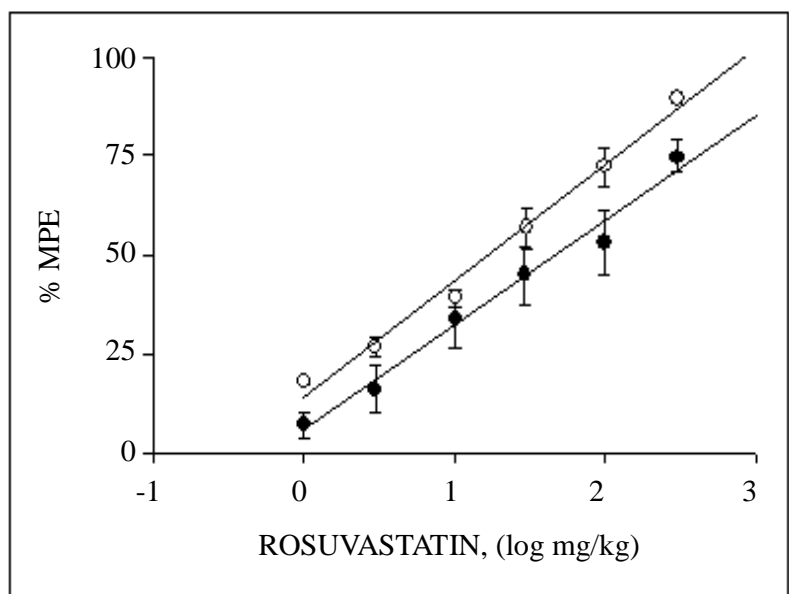

(c)

Figure 1. Dose-response curves for the antinociceptive activity induced by p.o. administration of rosuvastatin during 1 day (•) and 3 days $(0)$ in the writhing (a), tail-flick (b) and hot plate (c) test in mice. Each point represents the mean \pm S.E.M. of 8 animals. \% MPE = antinociception expressed as percentage of maximum possible effect.

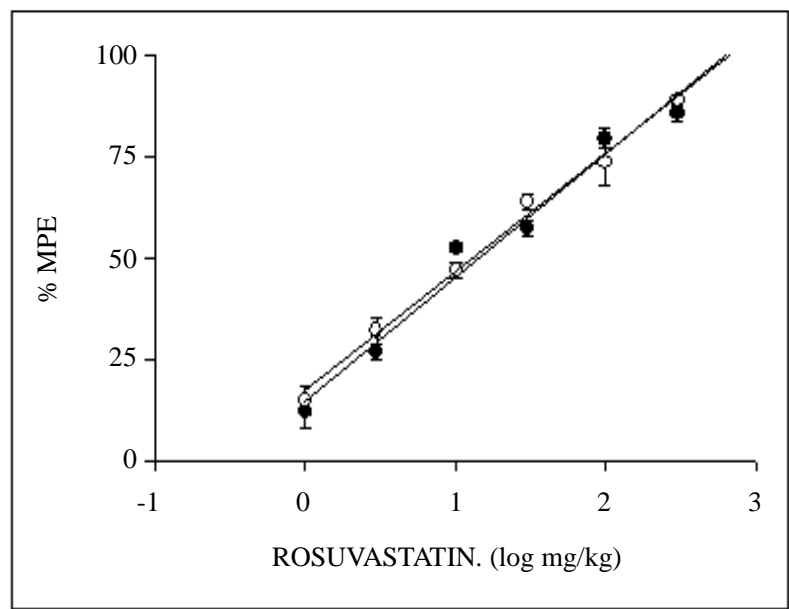

(a)

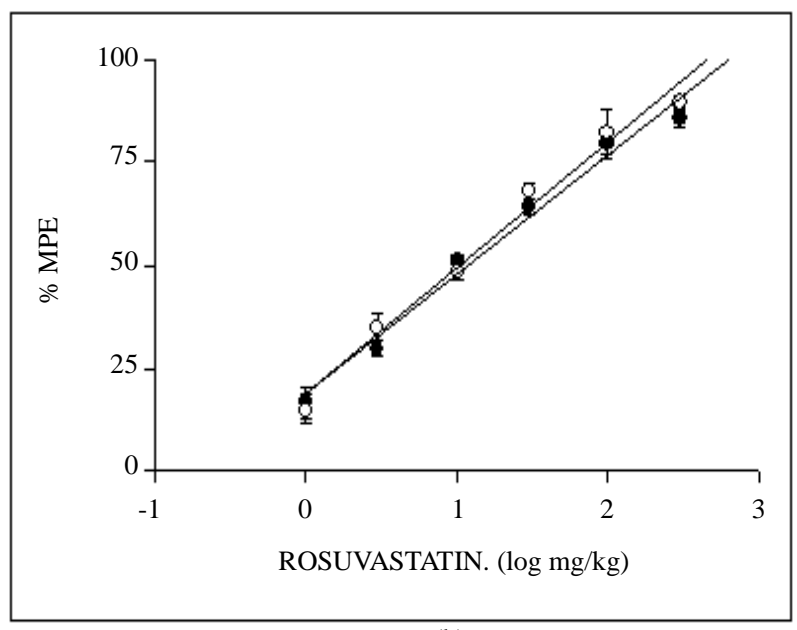

(b)

Figure 2. Dose-response curves for the antinociceptive activity induced by p.o. administration of rosuvastatin during 1 day (a) and 3 days (b) in the orofacial formalin test in mice during phase $I(\bullet)$ and phase II (O). Each point represents the mean \pm S.E.M. of 8 animals. \% MPE = antinociception expressed as percentage of maximum possible effect. 


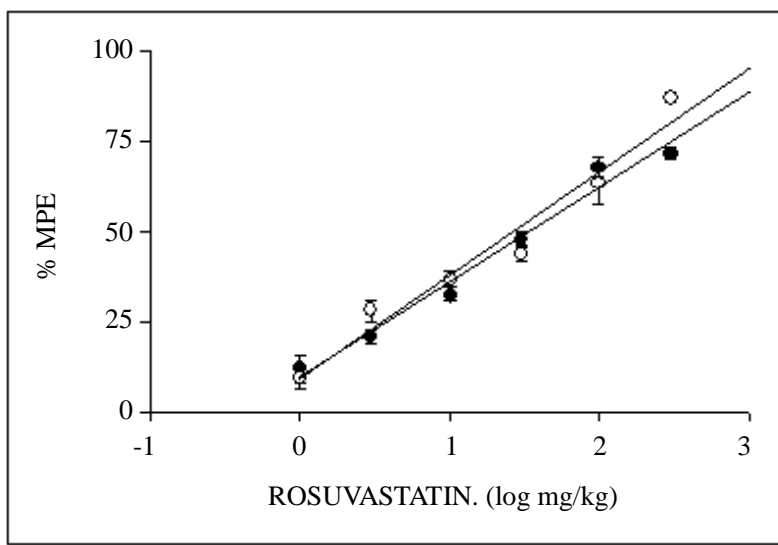

(a)

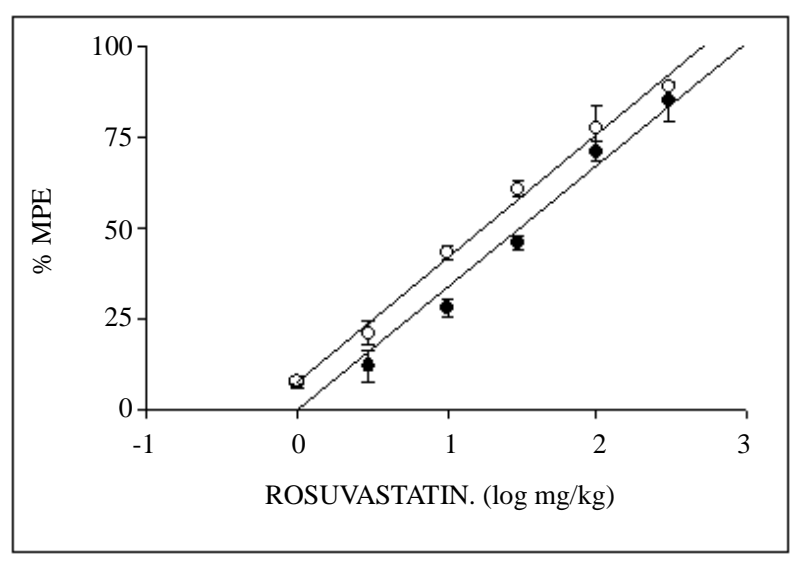

(b)

Figure 3. Dose-response curves for the antinociceptive activity induced by p.o. administration of rosuvastatin during 1 day (a) and 3 days $(b)$ in the formalin hind paw test in mice during phase $I(\bullet)$ and phase II (O). Each point represents the mean \pm S.E.M. of 8 animals. \% MPE = antinociception expressed as percentage of maximum possible effect.

phase I on days 1 and 3 respectively and $26.31 \pm 5.29$ and $17.37 \pm 1.36 \mathrm{mg} / \mathrm{kg}$, in phase II at days 1 and 3 respectively. Rosuvastatin was 1.13 and 1.51 fold more potent at days 1 than 3 , in phase I and II, respectively. The anti-inflammatory effect of rosuvastatin after the pretreatment of mice with 1 or $5 \mathrm{mg} / \mathrm{kg}$, i.p. of L-NAME was inhibited significantly with an $\mathrm{ED}_{50}$ of $92.98 \pm 0.78$ and $82.66 \pm 5.81 \mathrm{mg} / \mathrm{kg}$, in phase I at days 1 and 3, respectively and to $38.12 \pm 3.71$ and $75.64 \pm 6.32 \mathrm{mg} / \mathrm{kg}$, in phase II at days 1 and 3, respectively, as can be seen in see Table 1. If the antiinflamatory activity of rosuvastatin was measured in the presence of 50 or $100 \mathrm{mg} / \mathrm{kg}$ of aminoguanidine the $\mathrm{ED}_{50}$ were of $110.24 \pm 12.36$ and $125.57 \pm 8.59$ in phase I at days 1 and 3 , respectively and to $135.84 \pm 9.87$ and $158.39 \pm 8.21 \mathrm{mg} / \mathrm{kg}$, in phase II at days 1 and 3 , respectively (see Table 1 ).

After 1 day of pretreatment with equi-effective doses of rosuvastatin, the following rank of potency was found: orofacial formalin test, phase II $>$ orofacial formalin test, phase I $>$ writhing test $>$ formalin hind paw test, phase II > formalin hind paw, phase I assay $>$ hot-plate test $>$ tailflick test.

However, after 3 days of pretreatment with equi-effective doses of rosuvastatin, the following rank of potency was exhibited: orofacial formalin test, phase II > orofacial formalin test, phase I $>$ formalin hind paw, phase II assay $>$ writhing test $>$ formalin hind paw, phase I assay $>$ hot-plate test $>$ tail-flick test.

\section{Discussion}

The results of the present study confirm previous works in which the antinociceptive and antiinflammatory effects of statins in animal models of nociception were demonstrated [2-4,11]. However, the contradictory antinociceptive activity of rosuvastatin in the hot-plate test
[4], could be due to the use of a different protocol.

The findings of this study demonstrate that rosuvastatin is 1.3 to 8.1 times more potent than simvastatin and 1.3 to 2.4 times more potent than atorvastatin in the same assays under the similar experimental conditions and using the same doses $[2,3]$. The higher potency of rosuvastatin could be due to the fact that this hydrophilic statin is a sulfur-containing multiple sites that form a strong interaction with 3-hydroxy-methyl-glutaryl coenzyme A reductase (HMG-CoAR) and therefore provide more potent enzyme inhibition than other statins $[12,13]$. The increase in reaction time of the mice in the hot plate assay induced by rosuvastatin indicates that this statin act via central pain receptors [14]. The administration of acetic acid induces nociception by increasing at the peritoneum the levels of prostaglandins $[15,16]$.

The inhibition induced by rosuvastatin in the number of writhes produced by the administration of acetic acid solution in the mice, suggests the involvement of peripheral pain receptors. In the present study rosuvastatin displayed significant anti-inflammatory activities in the models of pain inflammation: formalin hind paw and orofacial formalin. The activity of rosuvastatin could be due, as atorvastatin, to the inhibition of the release of substance $\mathrm{P}$ and bradikinin, in phase I and prostaglandins, histamine and serotonin, in phase II $[17,18]$.

The findings of this study related to the antinociceptive and anti-inflammatory effects induced by rosuvastatin, in addition to their beneficial lipid modulation effects, may be due to the fact that rosuvastatin exerts a variety of several so-called "pleiotropic" actions that may result in clinical benefits. Many of the pleiotropic effects of rosuvastatin are anti-inflammatory, and a great number of experimental and clinical studies have indicated favorable effects of rosuvastatin on endothelial function, oxidized low-density lipoprotein, inflammation, plaque 
stability, vascular remodeling, hemostasis, cardiac muscle, and components of the nervous system [19-21].

Furthermore, it has been reported that the pain-alleviating effects of statins are likely attributable to their immunomodulatory effects, which suggest a potential new application of statins in the treatment of neuropathic pain, since systemic daily administration of rosuvastatin completely prevented the development of mechanical allodynia and thermal hyperalgesia. The administration after injury, reduced established hypersensitivity. It has been reported that rosuvastatin was able to abolish interleukin- $1 \beta$ expression in sciatic nerve triggered by nerve ligation. Additionally, it significantly reduced the spinal microglial and astrocyte activation produced by sciatic nerve injury [22].

Another possible explanation for the action of rosuvastatin induced in this study, may be related with the suggestion that statin regulated few inflammatory' genes, such as the proteins orosomucoid (ORM1) or interleukin 18 receptor accessory protein (IL18RAP) genes. The small number of statin-induced differences, both during treatment and after E. coli lipopolysaccharide induced inflammation, however, suggests that statins might exert their anti-inflammatory action mainly at the post-transcriptional level rather than at the level of gene transcription. This fact was proposed from a randomized, double-blind, placebo-controlled, crossover study conducted in six healthy male volunteers, pretreated with rosuvastatin before infusion of $E$. coli lipopolysaccharide [23].

Furthermore, NO has been implicated at various levels of the nociceptive neural pathways, either periferally and centrally, however, the implication of NO in the antinociception is controversial, thus it has been demonstrated that inhibition of NO has antinociceptive effects in chemical, thermal or visceral pain assays [24-26]. The antinociception obtained with rosuvastatin in this work is concordant with the previous studies in acetic acid writhing test and formalin test but not in the hot-plate test [4]. The difference results in the hot-plate could be due to a different protocol used.

The increase of the all $\mathrm{ED}_{50}$ of the different assays, after the pretreatment with L-NAME, $1 \mathrm{mg} / \mathrm{kg}$ or $5 \mathrm{mg} / \mathrm{kg}$, either at 1 day or 3 days, is indicative of the involvement of NO in the modulation of action of rosuvastatin. However, the results obtained by the use of aminoguanidine suggest that antiinflamatory activity of rosuvastatin can be induced by modulation of iNOS expression, since it has been demonstrated that iNOS is related with inflammatory pain [24].

In conclusion, the data obtained in the present study indicate that rosuvastatin decreases the nociception and the inflammation in the mice algesiometer-behavioural assays, with a nitridergic contribution in these effects.
These results could facilitate a possible clinical role of rosuvastatin in the treatment of human pain, such as neurophatic or anti-inflammatory disease.

\section{Acknowledgements}

This work was supported by project DI-02-11/CB from Universidad Andres Bello. The expert technical assistance of José López and Alejandro Correa is gratefully acknowledged.

\section{Conflict of Interest}

All the authors of this paper declare no conflict of interest

\section{REFERENCES}

[1] C. Argoff, "Mechanisms of Pain Transmission and Pharmacologic Management," Current Medical Research Opinion, Vol. 27, No. 10, 2011, pp. 2019-2031. http://dx.doi.org/10.1185/03007995.2011.614934

[2] C. G. García, H. F. Miranda, V. Noriega, F. Sierralta, L. Olavarría, R. Zepeda and J. C. Prieto, "Antinociception Induced by Atorvastatin in Different Pain Models," Pharmacology Biochemistry and Behavior, Vol. 100, No. 1, 2011, pp. 125-129.

http://dx.doi.org/10.1016/j.pbb.2011.08.007

[3] H. F. Miranda, V. Noriega, L. Olavarría, R. J. Zepeda, F. Sierralta and J. C. Prieto, "Antinociception and Anti-Inflamation Induced by Simvastatin in Algesiometric Assays in Mice," Basic \& Clinical Pharmacology \& Toxicology, Vol. 109, No. 6, 2011, pp. 438-442. http://dx.doi.org/10.1111/j.1742-7843.2011.00746.X

[4] M. M. Ghaisas, P. R. Dandawatew, S. A. Zawar, Y. S. Ahire and S. P. Gandhi, "Antioxidant, Antinociceptive and Antiinflammatory Activities of Atorvastatin and Rosuvastatin in Various Experimental Models," Inflammopharmacology, Vol. 18, No. 4, 2010, pp. 169-177. http://dx.doi.org/10.1007/s10787-010-0044-6

[5] M. Landsberger, F. Jantzen, S. Könemann and S. B. Felix, "Blockade of Geranylgeranylation by Rosuvastatinupregulatesenos Expression in Human Venous Endothelial cells," Biochemistry Biophysics Research Communications, Vol. 336, No. 4,2005, pp. 1005-1009. http://dx.doi.org/10.1016/j.bbrc.2005.08.225

[6] P. Di Napoli, A. A.Taccardi, A. Grilli, M. A. De Lutiis, A. Barsotti, M. Felaco and R. De Caterina, "Chronic Treatment with Rosuvastatin Modulates Nitric Oxide Synthase Expression and Reduces Ischemia-Reperfusion Injury in Rat Hearts," Cardiovascular Research, Vol. 66, No. 3, 2005, pp. 462-471.

http://dx.doi.org/10.1016/j.cardiores.2005.02.008

[7] S. P. Jones, M. F. Gibson, D. M. Rimmer, T. M. Gibson, B. R. Sharp and D. J. Lefer, "Preclinical and Clinical Pharmacology of Rosuvastatin, a New 3-Hydroxy-3Methylglutaryl Coenzyme a Reductase Inhibitor,” American Journal of Cardiology, Vol. 87, No. 5, 2001, pp. 28B-32B. 
http://dx.doi.org/10.1016/S0002-9149(01)01454-0

[8] P. Luccarini, A. Childereric, A. M. Gayder, D. Voisin and R. Dallel, "The Orofacial Formalin Test in the Mouse, a Behavioural Model for Studying Physiology and Modulation of Trigeminal Nociception,” Journal of Pain, Vol. 7, No. 12, 2006, pp. 908-914. http://dx.doi.org/10.1016/j.jpain.2006.04.010

[9] M. C. Berenbaum, "What Is Synergism?” Pharmacology Review, Vol. 41, No. 2, 1989, pp. 93-141.

[10] H. F. Miranda, M. M. Puig, M. A. Romero and J. C. Prieto, "Effects of Tramadol and Dexketoprofen on Analgesia and Gastrointestinal Transit in Mice,” Fundamental and Clinical Pharmacology, Vol. 23, No. 1, 2009, pp. 81-88. http://dx.doi.org/10.1111/j.1472-8206.2008.00636.x

[11] T. Santodomingo-Garzón, T. M. Cunha, W. A. Verri Jr, D. A. Valério, C. A. Parada and S. Poole, "Atorvastatin Inhibitits Inflammatory Hipernociception,” British Journal of Pharmacology, Vol. 149, No. 1, 2006, pp. 14-22. http://dx.doi.org/10.1038/sj.bjp.0706836

[12] G. Weitz-Schmidt, "Statins as Anti-Inflammatory Agents," Trends Pharmacological Sciences, Vol. 23, No. 10, 2002, pp. 482-487. http://dx.doi.org/10.1016/S0165-6147(02)02077-1

[13] U. Schonbeck and P. Libby, "Inflammation, Immunity, and HMG-CoA Reductase Inhibitors: Statins as Antiinflamatory Agents?” Circulation, Vol. 109, No. 1, 2004, pp. 18-26.

[14] N. D. Eddy and D. Leimback, "Synthetic Analgesics. II. Dithyienylbutenyl-Amines and Dithyienylbutylamine," Journal of Pharmacology and Experimental Therapeutics, Vol. 3, No. 2, 1953, pp. 544-547.

[15] D. L. Simmons, R. M. Botting and H. L. A. Timothy, "Cyclooxygenase Isozymes: The Biology of Prostaglandin Synthesis and Inhibition,” Pharmacology Review, Vol. 56, No. 3, 2004, pp. 387-437. http://dx.doi.org/10.1124/pr.56.3.3

[16] K. Lee and E. Choi, “Analgesic and Anti-Inflammatory Effects of Liguria Fischeri Leaves in Experimental Animals," Journal of Ethnopharmacology, Vol. 120, No. 1, 2008, pp. 103-107. http://dx.doi.org/10.1016/j.jep.2008.07.038

[17] H. Wheeler-Aceto and A. Cowean, "Neurogenic and Tissue Mediated Components of Formalin Induced Edema: Evidence for Supraspinal Regulation,” Agents and Action,

\section{Abbreviations}

HMG-CoA: 3-hydroxy-3 methylglutaryl coenzyme A reductase;

L-NAME: $\mathrm{N}^{\mathrm{G}}$-nitro-L-arginine methyl ester hydrochloride;

iNOS: inducible nitric oxide synthase;

NSAIDs: nonsteroidal anti-inflammatory drugs;

NO: nitric oxide;
Vol. 34, No. 2, 1991, pp. 264-269.

http://dx.doi.org/10.1007/BF01993299

[18] J. Sawynok and A. Ried, "Modulation of Formalin-Induced Behaviors and Edema by Local and Systemic Administration of Dextromethorphan, Memantine and Ketamine,” European Journal of Pharmacology, Vol. 450, No. 1, 2002, pp. 153-162. http://dx.doi.org/10.1016/S0014-2999(02)02119-2

[19] M. S. Elkind, "Inflammation, Atherosclerosis, and Stroke," Neurologist, Vol. 12, No. 1, 2006, pp. 140-148. http://dx.doi.org/10.1097/01.nrl.0000215789.70804.b0

[20] M. S. Kostapanos, H. J. Milionis and M. S. Elisaf, “An Overview of the Extra-Lipid Effects of Rosuvastatin,” Journal of Cardiovascular Pharmacology and Therapeutics, Vol. 13, No. 1, 2008, pp. 157-174. http://dx.doi.org/10.1177/1074248408318628

[21] R. Kones, "Rosuvastatin, Inflammation, C-Reactive Protein, JUPITER, and Primary Prevention of Cardiovascular Disease-A Perspective,” Drug Design Development and Therapy, Vol. 4, No. 3, 2010, pp. 383-413. http://dx.doi.org/10.2147/DDDT.S10812

[22] W. M. Schmidt, A. O. Spiel, B. Jilma, M. Wolzt and M. Müller, "In-Vivo Effects of Simvastatin and Rosuvastatin on Global Gene Expression in Peripheral Blood Leucocytes in a Human Inflammation Model," Pharmacogenetics Genomics, Vol. 18, No. 1, 2008, pp. 109-120. http://dx.doi.org/10.1097/FPC.0b013e3282f44d81

[23] X. Q. Shi, T. K. Lim, S. Lee, Y. Q. Zhao and J. Zhang, "Statins Alleviate Experimental Nerve Injury-Induced Neuropathic Pain,” Pain, Vol. 152, No. 5, 2011, pp. 1033-1043. http://dx.doi.org/10.1016/j.pain.2011.01.006

[24] J. V. Espluges, "NO as a Signalling Molecule in the Nervous System," British Journal of Pharmacology, Vol. 135, No. 5, 2002, pp. 1079-1095. http://dx.doi.org/10.1038/sj.bjp.0704569

[25] Y. Chen, M. K. Boettger, A. Reif, A. Schmitt, N. Uçeyler and C. Sommer, "Nitric Oxide Synthase Modulates CFAInduced Thermal Hyperalgesia through Cytokine Regulation in Mice," Molecular Pain, Vol. 2, No. 1, 2010, pp. 6-13.

[26] J. Kopincová, A. Púzserová and I. Bernátová, "L-NAME in the Cardiovascular System-Nitric Oxide Synthase Activator?” Pharmacology Reports, Vol. 64, No. 3, 2012, pp. 511-520.

MPE: maximum;

IL18RAP: interleukin 18 receptor accessory protein;

WT: writhing test;

TF: tail flick;

FP: formalin hind paw;

OF: orofacial formalin;

HP: hot plate;

AMG: aminoguanidine. 